\title{
Perancangan User Interface Design dan User Experience Mobile Responsive Pada Website Perusahaan
}

\author{
Moh. Dani Ariawan, Agung Triayudi*, Ira Diana Sholihati \\ Fakultas Teknologi Komunikasi dan Informasi, Informatika, Universitas Nasional, Jakarta, Indonesia \\ Email: ${ }^{1}$ muh.dani12@gmail.com, ${ }^{2, *}$ agungtriayudi@civitasunas.unas.ac.id, 3 iradiana2803@gmail.com \\ *) Email Penulis Korespondensi: agungtriayudi@civitasunas.unas.ac.id
}

\begin{abstract}
Abstrak-Metode Human-Centered Design merupakan sebuah metode pendekatan dalam pengembangan dan perancangan sebuah sistem yang berfokus pada pengguna sesuai aspek - aspek kebutuhan dan kebiasaan dari pengguna. Kesulitaan dalam mengakses informasi pada website menjadi sebuah permasalahan yang dihadapi oleh user dan dari segi visual website belum bisa responsive ketika di akses melalui mobile. Tahapan awal yang dilakukan pada metode ini adalah observasi yang bertujuan untuk mencari dan untuk lebih memahami permasalahan yang dihadapi oleh user hingga melakukan testing untuk mengetahui apakah solusi yang diberikan dapat dipahami dan mudah digunakan oleh user. Pengujian website dilakukan dengan memberikan tugas - tugas pada user untuk melakukan interaksi pada prototype website, sebagai hasil akhir keberhasilan dalam aspek kemudahan dan kenyamanan user menggunakan website tersebut. Setelah dilakukan pengujian kepada user secara langsung didapatkan hasil pengujian, yaitu user sudah merasa cukup paham dan mudah ketika menggunakan website yang sudah dibuat. Fitur mobile responsive yang dibuat juga membuat user merasa terbantu ketika sedang menggunakan website pada smartphone.
\end{abstract}

Kata Kunci: User Interface, User Experience, Human - Centered Designe, Website

\begin{abstract}
Human-Centered Design Method is a method of approach in the development and design of a system that focuses on the user according to aspects of the needs and habits of the user. Difficulty in accessing information on the website becomes a problem faced by the user and in terms of visual website can not be responsive when accessed via mobile. The initial stage carried out in this method is observation which aims to find and to better understand the problems faced by users to conduct testing to find out whether the solutions provided can be understood and easily used by the user. Website testing is done by giving tasks to the user to interact on the website prototype, as the final result of success in the aspect of ease and comfort of the user using the website. After testing the user directly the test results are obtained, ie the user already feels quite understanding and easy when using the website that was created. The responsive mobile feature created also makes users feel helped when using a website on a smartphone.
\end{abstract}

Keywords: User interface, User experience, Human - Centered Design, Website

\section{PENDAHULUAN}

Perkembangan teknologi di era 4.0 yang semakin cepat dan maju menuntut kita semua untuk terus bisa berinovasi dalam membuat sebuah produk teknologi, Baik teknologi berbasis aplikasi mobile ataupun website. Sudah banyak perusahaan - perusahaan yang memanfaatkan website sebagai alat untuk memperkenalkan profile mereka, contohnya adalah kantor Kementerian Energi dan Sumber Daya Mineral Direktorat Jenderal ketenagalistrikan.

Direktorat jenderal ketenagalistrikan bertugas menyelengarakan perumusan dan pelaksanaan kebijakan di bidang pembinaan, pengusahaan, keteknikan, keselamatan kerja, dan lingkungan di bidang ketenalaglistrikan. Untuk memberikan sarana informasi Direktorat jenderal ketenagalistrikan menggunakan media website sebagai sarana untuk memberikan informasi mengenai struktur organisasi, sejarah singkat, dan berita.

Masalah yang muncul pada penggunaan website sebagai media informasi pada kantor kementrian ketenagalistrikan adalah masih banyaknya user yang kesulitan dalam menggunkan website tersebut, hal ini menjadi sebuah masalah penting dari sisi kenyamanan user [1] dalam mencari informasi yang ada pada website tersebut. Dari segi visual pada website direktorat jendral ketenagalistrikan juga terlihat kurang menarik. Website juga belum responsive ketika user mengaksesnya melalui mobile, hal ini menjadi sangat penting mengingat dizaman yang serba cepat seperti saat ini user juga sering mengakses informasi apapun melalui mobile[2].

Metode pendekatan Human-Centered Design merupakan sebuah metode pendekatan didalam pengembangan dan perancangan sebuah sistem yang sangat berfokus kepada pengguna[3]. Dalam penerapan Human-Centered Design seorang desainer diwajibkan memperhatikan aspek-aspek kebutuhan dan kebiasaan dari user yang menjadi fokus terciptanya produk[4].

Berfokus pada permasalahan diatas, maka penulis membuat sebuah solusi dengan melakukan pengembangan pada website dari sisi visual dengan membuat tampilan yang lebih responsive ketika di akses melalui mobile sesuai dengan aspek aspek user interface[5].

Untuk memudahkan pengguna dalam memahami dan memberikan kemudahan dan kenyamanan dalam mengakses website tersebut sesuai dengan aspek aspek user experience[6]. Tujuan utama dari penelitian ini adalah penulis akan menerapkan aspek-aspek user interface dan user experience pada pengembangan website[7] Kementerian Eenergi dan Sumber daya Mineral Direktorat Jenderal Ketenagalistrikan dengan menggunakan metode $\mathrm{HCD}[8]$ dan diharapkan dengan adanya penerapan user interface dan user experience pada pengembangan website, user dapat lebih nyaman dan mudah dalam menggunakannya untuk memaksimalkan informasi yang 
nantinya akan didapatkan oleh user dalam website tersebut[9]. Dan diharapkan dapat menghasilkan website dengan visual yang lebih modern, user friendly dan responsive ketika digunakan pada mobile[10].

\section{METODE PENELITIAN}

Studi literature digunakan untuk mencari pembahasan yang berkaitan dengan topik yang akan di angkat, refrensi yang dipakai sebagai rujukan pada penelitian ini yang berkaitan dengan user interface dan user experience beserta metode Human - Centered Designe.

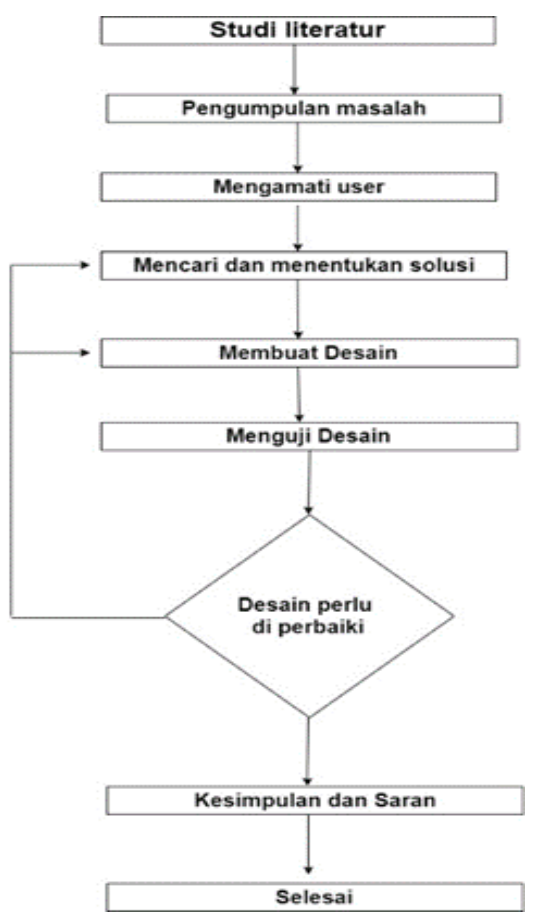

Gambar 1. Diagram alir

Setelah mendapat dan memahami referensi kemudian mulai dilakukan proses pengumpulan masalah yang dihadapi user, mengamati kebiasaan user, mencari dan menentukan solusi, dan mulai merancang desain sebagai solusi. Setelah itu dilakukan pengujian terhadap desain solusi kepada user, jika user masih di rasa kesulitan ketika memakai desain solusi maka akan dilakukan perbaikan. Namun jika user sudah berhasil dan tidak menghadapi kesulitan apapun, maka dibuatlah sebuah kesimpulan dan saran untuk proses pengembangan serta perbaikan dari penelitian ini.

Perangkat dan software yang dibutuhkan adalah :

a. Hardware dan Spesifikasi Hardware

Laptop ASUS A405U

Ram 8GB

Hdd $1 \mathrm{~TB}+128 \mathrm{~GB}(\mathrm{SSD})$

OS Windows 10

CPU Intel Core i5-7200U, up to $3.18 \mathrm{~Hz}$

b. Software

Adobe Xd

Whimsical

Google Chrome

Sublime Text

c. Alat Tulis

Kertas

Pensil

Pulpen

\subsection{Perancangan sistem}

Pada flowchart dijelaskan bagaimana jalanya proses pada website ketika digunakan oleh user, alur prosesnya mulai ketika user membuka website lalu user memilih fitur yang dicari untuk mendapatkan informasi tentang kantor setelah user memilih fitur menunya user bisa langsung mendapatkan informasi yang diinginkan. 


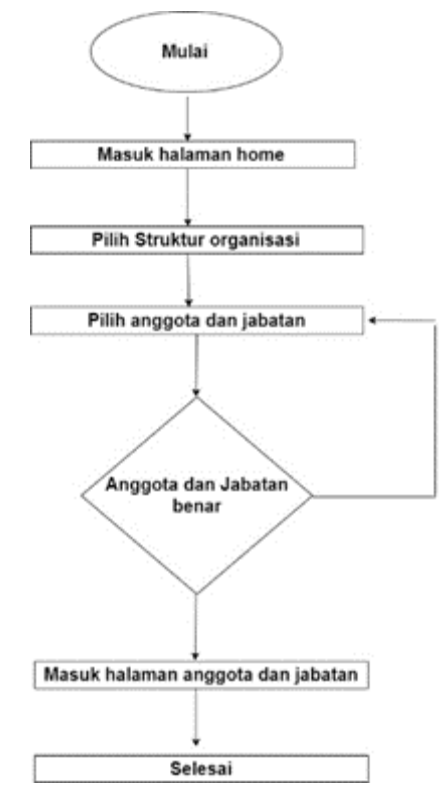

Gambar 2. Flowchart Proses

\section{HASIL DAN PEMBAHASAN}

\subsection{Pengumpulan Masalah Pada User}

Sebelum melakukan perancanga penulis akan melakukan Studi literature, studi literatur dilakukan untuk memperdalam teori permasalahan yang akan di angkat, yang bersumber dari jurnal dan internet.

Sebelum melakukan perancangan user interface penulis akan mencari tau apa saja masalah dan kebutuhan yang diperlukan oleh user dengan cara melakukan research, research dilakukan juga untuk mengetahui apasaja kebiasaan user ketika membuka website dan mencari tau fitur apa saja yang dibutuhkan oleh user dan masalah apa yang sering terjadi pada user ketika sedang menggunakan website. Research dilakukan dengan cara mewawancarai user secara langsung, agar penulis mendapatkan jawaban yang lebih banyak penulis memanfaatkan software online Google form dengan menggunakan software Google form penulis bisa mendapatkan jawaban yang lebih banyak.

\subsection{Membuat Wirefrime sebagai solusi}

Untuk mengurangi terjadinya kesalahan ketika melakukan designe dilakukan tahap awal yaitu membuat wireframe pada tahap ini juga dilakukan untuk mencari dan menentukan solusi, wireframe sendiri adalah membuat struktur dasar atau sketsa awal untuk tampilan desinge, pada tahap inilah ditentukan tata letak awal untuk tampilan website seperti tata letak fitur menu, gambar, icon, dan text. Wireframe bisa dibuat dengan menggunakan kertas atau bisa juga dibuat dengan menggunakan software whimsical.

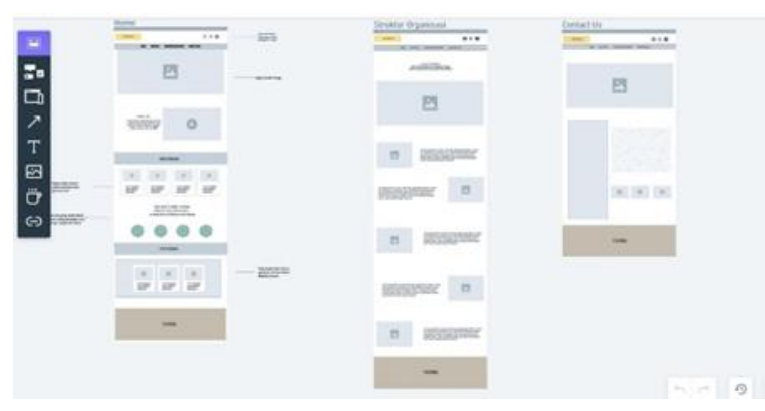

Gambar 3. Wireframe

\subsection{Membuat Tampilan Hight Fidelity}

Setelah proses wireframe sudah dianggap cukup baik, lanjut ketahap berikutnya yaitu membuat tampilan hight fidelity tahapan ini dilakukan untuk memberikan gambaran designe yang lebih jelas dimana pada designe hight fidelity ini mulai diberikan warna, gambar, menu, icon, dan teks. Pada tahap ini juga berfungsi untuk mempertegas tampilan pada website agar ketika diberikan kepada user, user memahami tampilan yang sudah dibuat, untuk membuat designe hight fidelity bisa menggunakan software figma, adobe xd, atau sketch. 
Available Online at https://ejurnal.stmik-budidarma.ac.id/index.php/mib DOI 10.30865/mib.v4i1.1896

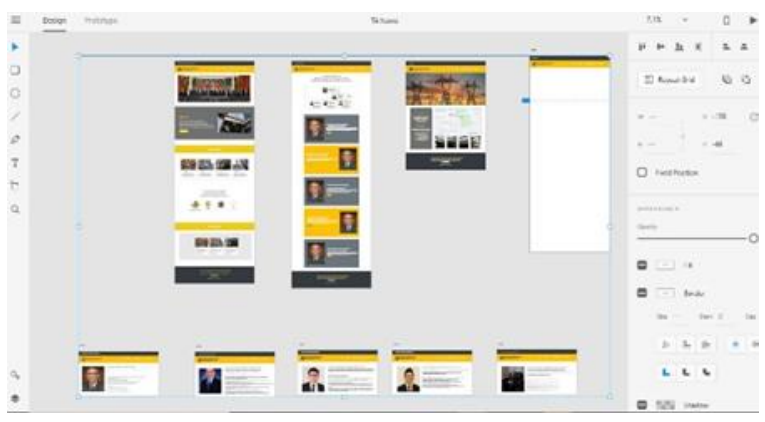

Gambar 4. Hight Fidelity

\subsection{Membuat Prototype}

Setelah proses perancangan desain hight fidelity sudah dirasa cukup langsung lanjut ketahap berikutnya yaitu membuat prototype, prototype dibuat untuk memudahkan user dalam memahami tampilan yang sudah dibuat. Dengan menggunakan prototype user bisa melakukan simulasi interaksi dengan tampilan yang sudah dibuat, prototype juga digunakan untuk memudahkan penulis ketika melakukan usability testing terhadap user.

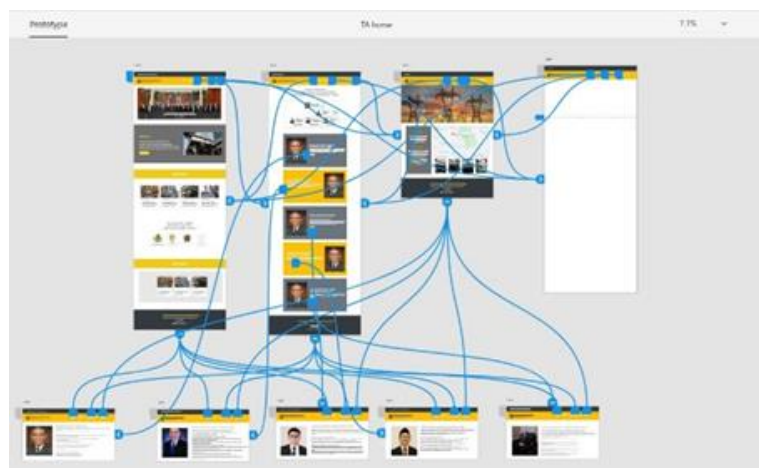

Gambar 5. Prototype

\subsection{Coding}

Tahap coding untuk memembuat tampilan pada website pada tahap coding ini menggunakan HTML,CSS dan Framework Bootstrap 4.0, HTML digunakan untuk membuat kerangka pada website setelah kerangka dibuat lalu diperjelas dengan menggunakan CSS, CSS berfungsi untuk mempercantik tampilan website agar website lebih rapih dan nyaman dipandang, agar website bisa digunakan di mobile penulis menggunakan Framework Bootstrap untuk membuat website menjadi responsive dengan memanfaatkan grid yang sudah disediakan pada bootstrap.

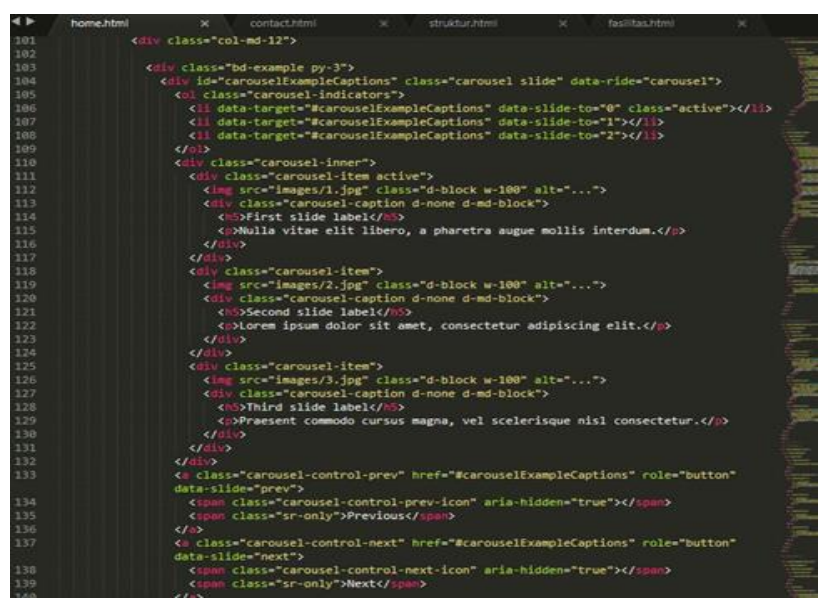

Gambar 6. Coding

\subsection{Halaman Home}

Halaman home adalah halaman awal pada website pada halaman home terdapat banyak fitur yang bisa memudahkan user dalam mencari info tentang kantor seperti About us, link terkait, foto dan video. Pada halaman home juga terdapat icon social media yang dapat klik untuk masuk langsung ke halaman social media kementerian direktorat jenderal ketenagalistrikan. 

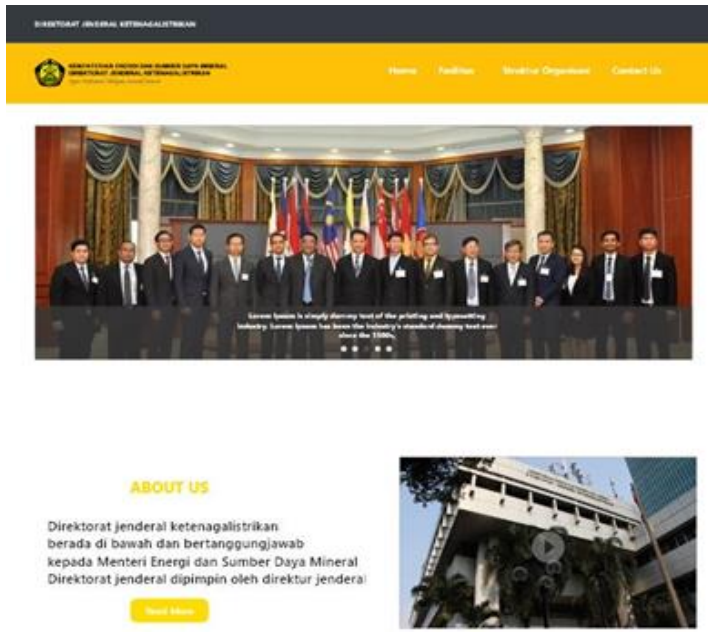

Gambar 7. Halaman Home

\subsection{Tampilan Pada Mobile}

Fitur mobile responsive dibuat untuk memudahkan user dalam menggunakan website pada smartphone, fitur mobile responsive juga dibuat untuk memudahkan user dalam mencari informasi yang terdapat pada website dengan menggunakan smartphone.

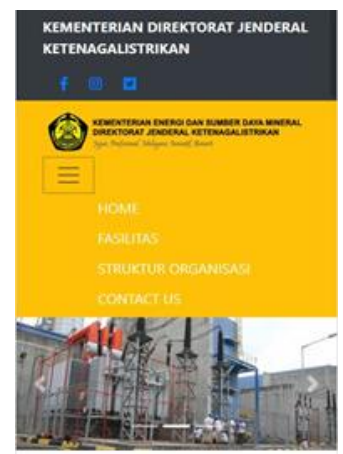

ABOUT US

Gambar 8. Tampilan pada mobile

\subsection{FeedBack Question}

FeedBack Question dibuat agar user bisa memberikan masukan dan saran yang bertujuan untuk mengetahui apasaja yang bisa dikembangkan dan diperbaiki pada prototype yang sudah dibuat.

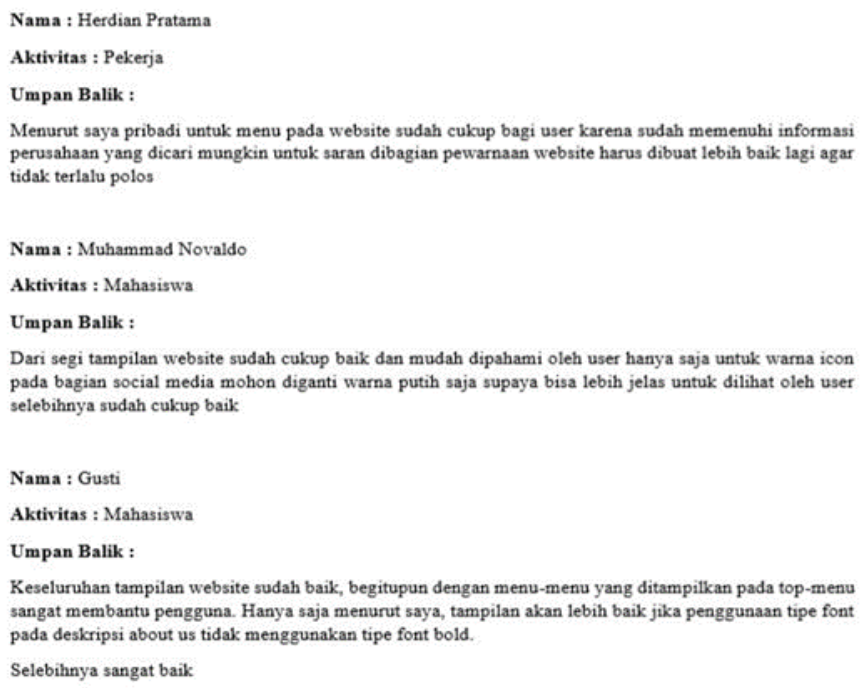

Gambar 9. FeedBack Question

Moh. Dani Ariawan, Copyright (C) 2020, MIB, Page 165 


\subsection{Hasil Pengujian}

Disini penulis melakukan pengujian langsung dengan cara mendatangi user dan user akan diberikan tugas untuk menggunakan prototype yang sudah dibuat, setelah user dirasa cukup ketika menggunakan prototype user akan diberikan tugas untuk memberikan penilaian tentang website tersebut apakah website sudah cukup dipahamai oleh user atau belum.

Tabel 1. Pengujian User

\begin{tabular}{lllll}
\hline No & Pertanyaan & Sangat Baik & Cukup Baik & Kurang Baik \\
\hline $\mathbf{1}$ & Tampilan pada website & $38.5 \%$ & $61.5 \%$ & - \\
$\mathbf{2}$ & Website dimengerti oleh user & $46.2 \%$ & $46.2 \%$ & $7.7 \%$ \\
$\mathbf{3}$ & Fitur Responsive yang dibuat & $53.8 \%$ & $46.2 \%$ & - \\
$\mathbf{4}$ & Fitur menu dapat membantu user & $38.5 \%$ & $46.2 \%$ & $15.4 \%$ \\
\hline
\end{tabular}

dari pengujian yang sudah dilakukan mendapatkan hasil cukup baik $46,2 \%$, Sangat baik $46,2 \%$, dan kurang baik $7,7 \%$.

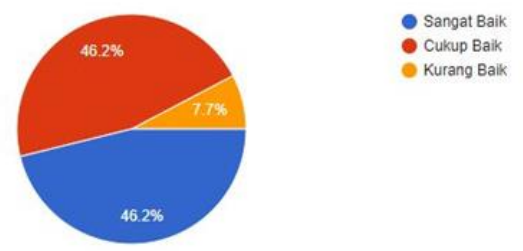

Gambar 10. Grafik Hasil Pengujian

\section{KESIMPULAN}

Dapat disimpulkan dengan adanya perancangan User Interface dan User Experience Design dapat memudahkan dan mempercepat pembuatan atau pengembangan suatu aplikasi dan website, dengan adanya UI dan UX dalam pembuatan suatu product digital dapat memudahkan developer dalam membangun productnya sebelum dilakukan coding dan publish ke user. Hasil yang didapat setelah melakukan pengujian langsung kepada user adalah user sudah cukup paham dengan tampilan website yang dibuat dan user juga sudah merasa cukup mudah dalam menggunakanya. Dan adanya fitur mobile responsive juga diharapkan dapat memudahkan user dalam mencari informasi pada website dengan menggunakan smartphone. Metode HCD (Humen Centered Designe) dapat digunakan untuk merancang dan membuat website yang sesuai dengan kebutuhan user.

\section{REFERENCES}

[1] N. Syahirsah, I. Aknuranda, and H. Aryadita, "Evaluasi dan Perbaikan Desain Antar Muka Pengguna Situs Talangin . com,” J. Pengemb. Teknol. Inf. dan Ilmu Komput. Univ. Brawijaya, vol. 2, no. 12, pp. 6618-6626, 2018.

[2] I. Muslim, "Perspektif Pengguna dalam Perancangan UserInterface pada Website Digital Library," J. Sains, Teknol. dan Ind., vol. 13, no. 1, pp. 39-45, 2015.

[3] Y. Firantoko, H. Tolle, and H. M. Az-zahra, "Perancangan User Experience Dengan Menggunakan Metode Human Centered Design Untuk Aplikasi Info Calon Anggota Legislatif 2019," J. Pengemb. Teknol. Inf. dan Ilmu Komput., vol. 3, no. 3, pp. 2798-2806, 2019.

[4] X. Sun and A. May, "Design of the User Experience for Personalized Mobile Services," Int. J. Hum. Comput. Interact., vol. 5, no. 2, pp. 21-39, 2014.

[5] F. Muhammad, R. A. Nugroho, and D. Turianto N, "Analisis User Experience Untuk Tingkat Keterpilihan Smartphone Android,” Kumpul. J. Ilmu Komput., vol. 04, no. 01, pp. 82-91, 2016.

[6] D. Prajarini and D. Sumberahayu, "PERANCANGAN PROTOTYPE WEB PROFILE DESA WISATA DAN KERAJINAN GAMPLONG SLEMAN DENGAN METODE DESAIN USER EXPERIENCE,” vol. 2, no. 1, pp. 249259, 2018.

[7] J. Saptari, R. Iswandari, and R. Setyawati, "User Experience (UX) dalam pemanfaatan fasilitas Informal Learning Space (ILS) perpustakaan,” Berk. Ilmu Perpust. dan Inf., vol. 14, no. 1, p. 26, 2018.

[8] D. M. Lestari, D. Hardianto, and A. N. Hidayanto, "Analysis of user experience quality on responsive web design from its informative perspective," Int. J. Softw. Eng. its Appl., vol. 8, no. 5, pp. 53-62, 2014.

[9] L. D. Farida, "Pengukuran User Experience Dengan Pendekatan Usability [Kasus: Website Pariwisata Di Asia Tenggara]," Semin. Nas. Teknol. Inf. dan Multimed., pp. 6-7, 2016.

[10] A. Iqbal, G. Prakasa, and F. Ardiansyah, "Perancangan User Experience Aplikasi Marketplace Paket Wisata Indonesia untuk Wisatawan Lokal User Experience Design of the Indonesia Tourism Package Marketplace Application for Local Tourist," J. Ilmu Komput. Agri-Informatika, vol. 5, no. 1, pp. 51-60, 2016. 